\title{
VOLUMETRIC ANALYSIS OF THE ARTICULAR EMINENCE PNEUMATIZATION USING CONE-BEAM COMPUTED TOMOGRAPHY
}

\begin{abstract}
Objectives: To assess tomographic features of articular eminence pneumatization (AEP) using cone beam computed tomography (CBCT).
\end{abstract}

Materials and Methods: To evaluate 659 CBCTs (500 women and 159 men) of the Oral and Maxillofacial Radiology service of Universidad Peruana Cayetano Heredia Dental Clinic, between 2014 - 2015. The age group was between 7 to 79 years-old. The classification of Al Faleh and Ibrahim was also used to assess the degree of pneumatization, and the statistical analysis was performed using the chi-square test.

Results: The frequency of AEP was $76.2 \%$ (502 cases). The highest frequency was found for grade 0 and 2 , the highest frequency was found in the 6th decade of life and great predominance was found for the female sex. However, no statically significant differences were found with respect to the gender.

Conclusions: AEP prevalence was $76.2 \%$ and CBCT became the goldstandard that allows an adequate evaluation of this anatomical variant.

Keywords: Cone-beam computed tomography, temporal bone, temporomandibular joint, zygoma.

\author{
Dilushka Quezada ${ }^{1}$ \\ (D) Jean Pierre Paucar-Oyola ${ }^{1}$ \\ (iD) Roberto León ${ }^{2}$ \\ (D) *Maria Eugenia Guerrero ${ }^{3}$
}

ORCID IDs of the authors:
$\begin{array}{ll}\text { M.Q. } & 0000-0002-7809-8744 \\ \text { J.P.P.O. } & 0000-0001-7902-6489 \\ \text { R.L. } & 0000-0001-9641-1047 \\ \text { M.E.G. } & 0000-0001-5425-870 X\end{array}$

1 Oral and Maxillofacial Radiology,
Postgraduate School, Universidad Peruana
Cayetano Heredia, Lima, Peru.
${ }^{2}$ Public Health and Dentistry Services
Management Research Unit, Social Dentistry
Department, School of Dentistry, Universidad
Peruana Cayetano Heredia, Lima, Peru.
${ }^{3}$ Department of Medico Surgical Stomatology,
Faculty of Dentistry, Universidad Nacional
Mayor de San Marcos, Lima, Perú.

Received : 05.03 .2021

Accepted : $: 02.05 .2021$ 


\section{INTRODUCTION}

In recent years Cone Beam Computed Tomography (CBCT) has been used with great frequency in the evaluation of bony structures of the skull. The image detail, the short examination time, the low cost and the lower exposure to radiation compared to conventional computed tomography (CT) has made it become the gold standard for the proper evaluation of the skull. ${ }^{1}$

The pneumatization process can be defined as a development of air within the bone cavities and can occur in numerous locations in the skull including the temporal bone. ${ }^{2}$ The mastoid antrum is the first cell of the mastoid air system to develop around the 4th and 5th month of intrauterine life. The pneumatization process begins around the 7 months of intrauterine life. During the post-natal development, the epithelium of the mastoid portion expands and begins its development 1 to 2 years after birth. ${ }^{3,4}$ Some authors, among them Groell and Fleischman ${ }^{5}$, reported that articular eminence pneumatization (AEP) occurs through a subepithelial bone resorption process. The complete pneumatization of mastoid cells can be divided into 3 stages: infantile stage, from birth to 2 years of age; the transitional stage, from 2 to 5 years; and the adult stage, after 5 years. ${ }^{2}$ The AEP can be in relation to the middle ear, the Eustachian tube and the mastoid structure, depending on the degree there may be repercussions in the cholesteatoma processes, chronic otitis and even in pathological or surgical procedures such as mastoidectomy. ${ }^{6}$ Another entity associated with the AEP is the middle-ear barotrauma, this entity is defined as the damage of the middle ear tissues where the Eustachian tube does not allow the entry of air into this structure producing a pressure difference between the middle ear and the surrounding environment. Uzun et al. $^{7}$ reported an inverse relationship between the size of pneumatization and risk of symptomatic middle ear barotrauma in sport scuba divers. This indicates that people with AEP are protected against a barotrauma since the mastoid cells act as shock absorbers before sudden changes in pressure.
Panoramic radiography and other conventional projections of the skull do not provide adequate visualization of the posterior aspect of the zygomatic arch due to the superposition of structures. These disadvantages have been overcome now, cone-beam CT (CBCT) has a great field of applications in dentistry, including preoperative implant planning, third molar imaging, temporomandibular joint (TMJ) evaluation, orthodontic treatment planning, and craniofacial anomaly estimation. In comparison to computed tomography (CT) they are cheaper and incur a lower radiation dose. Recently, a higher prevalence of temporal bone pneumatization around TMJ has been reported using CT. ${ }^{8}$

Within the radiographic features, AEP appears as radiolucent images of defined limits and of similar shape and size to the mastoid pneumatization (MP) air cells. These cells can appear unilaterally or bilaterally and present a unilocular or multilocular radiographic pattern. Also, they do not produce expansion or symptomatology, important characteristics to be able to rule out some pathologies such as an eosinophilic granuloma, hemangiomas or solitary bone cysts at this level. ${ }^{9}$ Several studies have classified the AEP, among them Han et al..$^{10}$ and Yamakami et al. ${ }^{11}$ However, few were made using CBCT. Recently, Shamshad et al. ${ }^{12}$ reported a prevalence of 52\% in India. In 2014, Nascimento et al. ${ }^{13}$ found a frequency of $3.3 \%$ in Brazil and Demirel et al. ${ }^{14}$ reported $67.6 \%$ in Turkey. In 2013, Delibasi et al. ${ }^{15}$ described $2.54 \%$ and Ladeira et al. ${ }^{1}$ found $21.3 \%$ in Brazil. The pneumatization pattern can affect any surgical procedures involving the skull base region. Pneumatization of the articular eminence is a challenging entity for TMJ surgery and spread of infections in this region. Practitioners who are dealing with TMJ surgery and pathology should need detailed information about this anatomical variation since it may cause serious complications. The aim of this study was to classify articular eminence pneumatization in adults using CBCT data sets in a peruvian population. 


\section{MATERIALS AND METHODS}

We designed a descriptive, transversal and retrospective study. This study used CBCT images of patients who were referred to the Oral and Maxillofacial Radiology Service at Universidad Peruana Cayetano Heredia, between February 2014 and December 2015. The study protocol (17.12.2014), was approved by the Institutional Ethics Committee of the Universidad Peruana Cayetano Heredia (CIE- UPCH). Selection criteria for patients (6 to 79 years of age) included images with field of view in which the right and left MP were adequately seen. Cases displaying cystic or tumoral pathologies in the temporal bone or maxillofacial fracture history were excluded from the study. The variables that were taken into account were age, gender, laterality (unilateral,bilateral), sides (right or left) and degree of pneumatization. Guidelines were drawn perpendicular to the axis of the condyle on axial views, and cross-sectional reconstructions were made perpendicular to these lines with 1-mm slice thicknesses and 1-mm slice intervals. Axial and sagittal sections were also used. For the degree of pneumatization, the $\mathrm{Al}$ Faleh and Ibrahim $^{16}$ classification was used, which is conformed by 4 grades ( 0 to 3 ): grade $0=$ pneumatization limited to the MP, grade 1=pneumatization between the MP to the deepest part of the glenoid fossa, grade $2=$ pneumatization between the deepest part of the glenoid fossa and the tip of the articular eminence and grade 3 = pneumatization extending beyond the crest of the articular eminence (Figure 1).

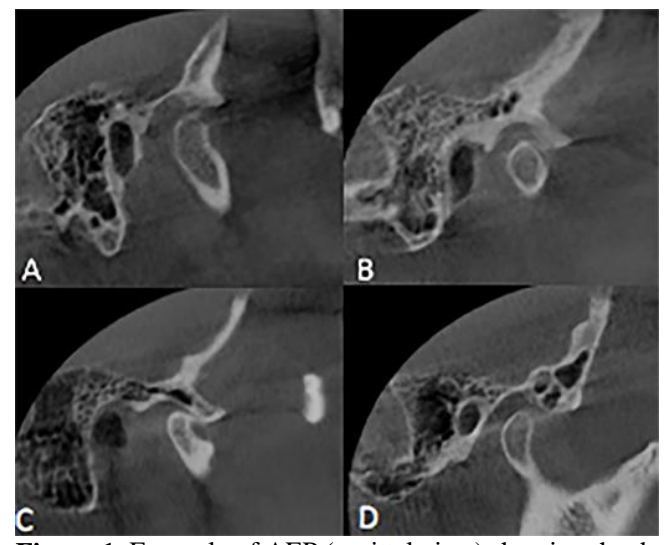

Figure 1. Example of AEP (sagittal view) showing the degree of pneumatization based on Al Faleh and Ibrahim ${ }^{16}$ classification. (A) Grade 0. (B) Grade 1. (C) Grade 2. (D) Grade 3.
The principal investigator was trained and calibrated by an oral and maxillofacial radiologist with more than 10 years of experience. This calibration was performed on 15 CBCT scans (Siemens, Germany). All the scans were acquired on a Galileos unit (Siemens, Germany) operating from $10 \mathrm{~mA}$ to $42 \mathrm{Ma}$ and $85 \mathrm{Kv}$ according to each patient, all the images were exported on a Lenovo H61 compatible computer and were evaluated through the Galaxis 1.7.2 software. The interobserver Kappa was 0.82 and 0.9 for the intraobserver agreement. $20 \mathrm{CBCTs}$ were evaluated per day on an inter-day basis in a dimmed room at a distance of $60 \mathrm{~cm}$ from the diagnostic viewing screen, with low ambient light and maximum of 2 hours per day. The digital images were analyzed on a 21-inch screen, with a resolution of $1600 \times 900$ pixels and 32-bit color depth.

\section{Statistical methods}

The collected data was statistically analyzed using SPSS ver.23 for Windows (IBM SPSS, Chicago, Illinois, USA). Frequency distribution tables were used for the variables sex, laterality, side and degree of pneumatization. For the bivariate analysis, the ChiSquare Test and the Yates-corrected Chi-square Test were used for the case of sex because it was a nonhomogeneous sample. The study had a confidence level of $95 \%$ and $p<0.05$.

\section{RESULTS}

The study population consisted of 659 CBCTs. There were 159 male patients and 500 female patients. The prevalence of AEP for the female gender was $58.3 \%$ (384 CBCTs) and for the male gender $17.9 \%$ with 118 CBCTs. Overall, 445 cases (33.8\%) had grade 0 pneumatization, 371 cases (28.1\%) had grade 1,432 cases $(32.8 \%)$ had grade 2 , and 70 cases $(5.3 \%$ ) had grade 3 . Regarding the AEP grade by gender, the highest prevalence was grade 0 followed by grade 2 for both genders. There was no significant relationship between the grade of pneumatization and $\operatorname{sex}(\mathrm{p}=0.82)$ (Table 1). 
Table 1. Distribution of AEP groups and sex groups

\section{Pneumatization grade}

\begin{tabular}{lcccccccc} 
Sex & \multicolumn{2}{c}{ Grade 0 } & \multicolumn{2}{c}{ Grade 1 } & \multicolumn{2}{c}{ Grade 2 } & & Grade 3 \\
\hline & $\mathbf{n}$ & $\%$ & $\mathbf{n}$ & \% & $\mathbf{n}$ & $\mathbf{\%}$ & $\mathbf{n}$ & \% \\
Male & 114 & 8.6 & 85 & 6.4 & 103 & 7.8 & 16 & 1.2 \\
Female & 331 & 25.1 & 286 & 21.7 & 329 & 25.0 & 54 & 4.1 \\
TOTAL & 445 & 33.8 & 371 & 28.1 & 432 & 32.8 & 70 & 5.3 \\
\hline
\end{tabular}

Yates-corrected Chi-square Test $(p=0.51)$.

For the AEP grade and the age group, the highest prevalence was on the 50-59 years-old group for

Age distribution by decade

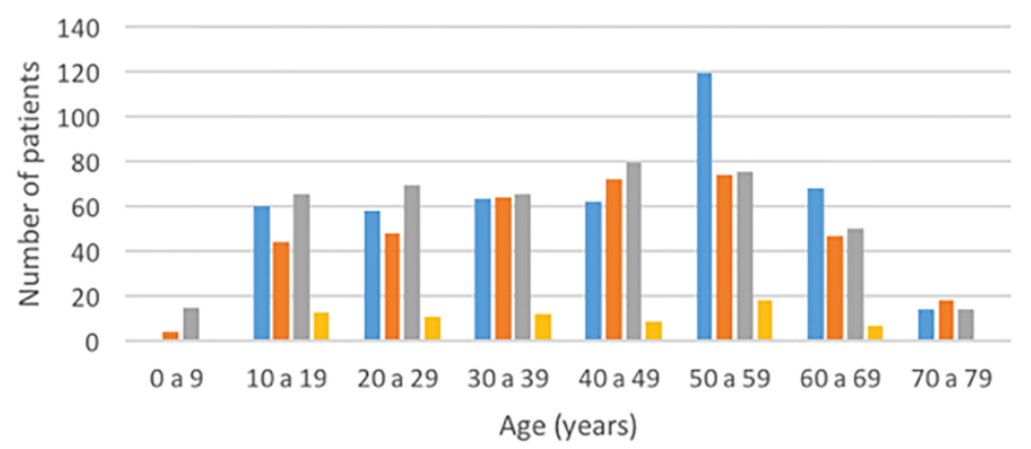

arade 0 Grade 1 G Grade 2 Grade 3

Figure 2. Frequency distribution of the AEP in relation to the age.

With respect to the side and frequency of the AEP grade, the most prevalent grade for the right side was grade 0 . For the left side, grade 2 was the grade 0 . For grade 2, the 40-49 years-old group had the highest prevalence (figure 2).

Table 3. Distribution of AEP groups and side

\section{Pneumatization grade}

\begin{tabular}{lcccccccc}
\multicolumn{1}{r}{ Side } & \multicolumn{2}{c}{ Grade 0 } & \multicolumn{2}{c}{ Grade 1 } & \multicolumn{2}{c}{ Grade 2 } & \multicolumn{2}{c}{ Grade 3 } \\
& $\mathbf{n}$ & $\boldsymbol{\%}$ & $\mathbf{n}$ & $\boldsymbol{\%}$ & $\mathbf{n}$ & $\boldsymbol{\%}$ & $\mathbf{n}$ & \% \\
\hline Right & 252 & 19.1 & 182 & 13.8 & 192 & 14.6 & 33 & 2.5 \\
Left & 193 & 14.6 & 189 & 14.3 & 240 & 18.2 & 37 & 2.8 \\
TOTAL & 445 & 33.8 & 371 & 28.1 & 432 & 32.8 & 70 & 5.3 \\
\hline
\end{tabular}

Chi-Square Test $(p<0.01)$.

In relation to laterality, grade 2 was the most prevalent grade found in bilateral cases. For one with the highest prevalence. A statistically significant difference was found between the AEP grade and the side (Table 3 ). 
Table 2. Distribution of laterality between the pneumatization groups

\section{Pneumatization grade}

\begin{tabular}{lcccccccc}
\multicolumn{1}{r}{ Laterality } & \multicolumn{2}{c}{ Grade 0 } & \multicolumn{2}{c}{ Grade 1 } & \multicolumn{2}{c}{ Grade 2 } & \multicolumn{2}{c}{ Grade 3 } \\
& $\mathbf{n}$ & $\boldsymbol{\%}$ & $\mathbf{n}$ & $\boldsymbol{\%}$ & $\mathbf{n}$ & $\boldsymbol{\%}$ & $\mathbf{n}$ & $\boldsymbol{\%}$ \\
\hline Absent & 157 & 100.0 & 0 & 0.0 & 0 & 0.0 & 0 & 0.0 \\
Unilateral & 128 & 49.6 & 84 & 32.6 & 40 & 15.5 & 6 & 2.3 \\
Bilateral & 3 & 0.4 & 287 & 38.5 & 392 & 52.5 & 64 & 8.6 \\
\hline
\end{tabular}

Chi-Square Test $(p<0.01)$.

\section{DISCUSSION}

The present study is one of the few studies available in South America and the first in our country using CBCT. This technique allows to evaluate and detect the AEP more precisely. ${ }^{13}$ The frequency of the AEP in the present study was $76.2 \%$ (502 cases) of 659 revised CBCTs. This result is similar to the one published by Demirel $e t$ $a l .{ }^{14}$ with a frequency of $67.6 \%$ (169 cases) of 250 revised CBCTs and to the study reported by Khojastepour et al. ${ }^{17}$ with a prevalence of $76.7 \%$ (251 cases) of 327 CBCT patients. On the other hand, a lower frequency of $6.47 \%$ (39 cases) was reported in the turkey population. ${ }^{9}$ Furthermore, Ladeira et al. ${ }^{1}$ and Delibasi et al. ${ }^{15}$ found $21.3 \%$ (140 cases) and $2.54 \%$ (21 cases) respectively in Brazil. Recently, Şallı et al. ${ }^{18}$ reported a prevalence of $14.7 \%$ (147 cases) of 1000 cases in a tukish population.

Regarding studies using CT, Groell and Fleischmann (9) found a frequency of $12 \%$ (12 cases) in Austria, and Bronoosh et al. ${ }^{19}$ found 9.55\% (43 cases) in Iran. Also, Al Faleh and Ibrahim $^{16}$ found $34 \%$ (102 cases) using conventional tomograms in Egypt. Only one study has reported a higher prevalence using CT $(69 \%$ of 100 cases) in India. ${ }^{12}$ Moreover, using panoramic radiography Shokri et al. ${ }^{20}$ and Khojastepour et al. ${ }^{8}$ found a frequency of $6.2 \%$ (98 cases) and 2.1\% (64 cases) respectively in Iran using panoramic radiography. In India, Kishore et $a l .{ }^{21}$ and Patil et al. ${ }^{22}$ found similar frequencies of $2.5 \%$ (63 cases) and $1.82 \%$ (141 cases) respectively. Orhan et al. ${ }^{2}$ reported a similar frequency of $1.88 \%$ (19 cases) to the ones reported by Hofmman et al. ${ }^{23}$ with a frequency of $2.38 \%$ (20 cases) and of $1.85 \%$ (20 cases) respectively in
Germany (Table 4). We have noticed that this anatomical variant increases its frequency when evaluated through CBCT. The improvement of the image and the advance on the techniques can contribute to an adequate evaluation. Therefore, the frequency of AEP can be increased.

Our study showed a greater predilection of AEP on females. Nevertheless, there was no statistically significant difference. Similar results were reported by other authors. ${ }^{6,16,23-25}$ On the other hand, Ladeira et al. ${ }^{1}$ found a slight predilection for the male gender with respect to the total of patients with AEP evaluated with CBCT. Some authors attribute a higher prevalence on the female sex because pneumatization begins with maturation, for this reason girls are chronologically and biologically older than children. Another theory may be due to the random recruitment performed at the time of the study.

Our findings detected more cases with AEP in the sixth decade of life with an age range of 7 to 79 years-old. In the present study, there was a statistically significant difference. Ladeira et al. ${ }^{l}$ found a similar result. This may be due to the main indication for taking CBCT, since most of the patients in the clinic are referred by the implantology area. Another theory according to Orhan et al. ${ }^{2}$ is that accessory air cells begin their pneumatization after puberty and end their development several years later, even in the adult stage.

Regarding the AEP localization, most studies found that there is a greater predilection for the left side, as reported in the present study where we found a statistically significant difference. However, other studies such as that of Patil et al. ${ }^{22}$, 
Bronoosh et al. ${ }^{19}$ and Carter et al..$^{24}$ found a greater predilection for the right side (Table 4).

Table 4. Percentages of articular eminence pneumatization from previous studies by sex, age, side and laterality

\begin{tabular}{|c|c|c|c|c|c|c|c|c|c|c|c|c|c|}
\hline \multirow[t]{2}{*}{ Author } & \multirow[t]{2}{*}{ Year } & \multirow[t]{2}{*}{ Coutry } & \multicolumn{4}{|c|}{ Sex } & \multirow{2}{*}{$\begin{array}{c}\text { Age } \\
\text { range } \\
\text { (Years) }\end{array}$} & \multirow{2}{*}{$\begin{array}{c}\text { Most } \\
\text { frequent } \\
\text { age group } \\
\text { (Years) }\end{array}$} & \multicolumn{2}{|c|}{$\begin{array}{c}\mathrm{N}^{\circ} \text { of cases by } \\
\text { side }\end{array}$} & \multirow[b]{2}{*}{ Unilateral } & \multirow[b]{2}{*}{ Bilateral } & \multirow[t]{2}{*}{$\begin{array}{l}\text { Imaging } \\
\text { Technique }\end{array}$} \\
\hline & & & Female & $\%$ & Male & $\%$ & & & Right & Left & & & \\
\hline Şallı et al. ${ }^{18}$ & 2020 & Turkey & 253 & 51.8 & 235 & 48.2 & $16-77$ & -- & 149 & 88 & 237 & 381 & СВCT \\
\hline $\begin{array}{l}\text { Khojastepour et } \\
\text { al. }{ }^{17}\end{array}$ & 2018 & Iran & 112 & 44.6 & 139 & 55.4 & $9-65$ & --- & 41 & 35 & 76 & 175 & СВСТ \\
\hline $\begin{array}{l}\text { Shamshad et } \\
\text { al. }{ }^{12}\end{array}$ & 2017 & India & 48 & 48 & 52 & 52 & $18-65$ & --- & 14 & 17 & 31 & 38 & CT \\
\hline Kishore et al. ${ }^{21}$ & 2015 & India & --- & ---- & ---- & ---- & $19-78$ & $29-38$ & 36 & 46 & 44 & 19 & PAN \\
\hline Demirel et al..$^{14}$ & 2014 & Turkey & 179 & 55.5 & 159 & 44.5 & ---- & --- & --- & ---- & --- & --- & --- \\
\hline $\begin{array}{l}\text { Bronoosh et } \\
\text { al. }{ }^{19}\end{array}$ & 2014 & Iran & --- & --- & --- & --- & --- & --- & 32 & 30 & 24 & 19 & CT \\
\hline $\begin{array}{l}\text { Khojastepour et } \\
\text { al. }{ }^{8}\end{array}$ & 2014 & Iran & 41 & 64 & 23 & 36 & $19-69$ & $19-29$ & --- & ---- & --- & --- & PAN \\
\hline Shokri et al. ${ }^{19}$ & 2013 & Iran & 65 & 66.4 & 33 & 33.6 & $8-60$ & $11-20$ & 30 & 34 & 64 & 34 & PAN \\
\hline Ladeira et al. ${ }^{1}$ & 2013 & Brasil & 75 & 37 & 129 & 63 & $11-85$ & $50-59$ & 94 & 110 & 76 & 64 & СBCT \\
\hline Patil et al. & 2012 & India & ---- & ---- & ---- & ---- & $19-75$ & $19-28$ & 96 & 79 & 107 & 34 & PAN \\
\hline Miloglu et al. ${ }^{9}$ & 2010 & Turkey & 25 & 54 & 14 & 46 & --- & --- & 12 & 21 & 23 & 16 & PAN \\
\hline Al Faleh et al. ${ }^{16}$ & 2005 & Egypt & 54 & 52.9 & 48 & 47.1 & --- & --- & 86 & 89 & ---- & --- & $\begin{array}{c}\text { Conventional } \\
\text { CT }\end{array}$ \\
\hline Orhan et al. $^{2}$ & 2005 & Turkey & 12 & 63.1 & 7 & 36.9 & $11-29$ & $20-29$ & ---- & ---- & ---- & --- & PAN \\
\hline $\begin{array}{l}\text { Hofmman et } \\
\text { al. }{ }^{22}\end{array}$ & 2001 & Germany & 11 & 55 & 9 & 45 & $7-87$ & $20-29$ & --- & --- & --- & --- & PAN \\
\hline Carter et al. ${ }^{23}$ & 1999 & USA & 20 & 50 & 20 & 50 & $17-83$ & $60-69$ & 25 & 23 & 32 & 8 & PAN \\
\hline
\end{tabular}

CBCT: Cone-beam CT, PAN:Panoramic radiography, CT: Computed tomography

Moreover, with respect to laterality a higher prevalence was found for unilateral presentations on CT, panoramic radiography and CBCT. However, Nascimento et al..$^{13}$ found a higher prevalence of bilateral presentations. Our study found a similar result, this can be due to the same time of development of both temporal bones. In the present study, a statistically significant difference was found with respect to AEP with regard to laterality (Table 4).

Finally, based on $\mathrm{Al}$ Faleh and Ibrahim ${ }^{16}$ mastoid cells classification, the highest prevalence was for grades 0 and grade 2 . With respect to the gender, females with grade 0 had the highest prevalence. However, no statistically significant differences were found. Statistically significant differences were found regarding the age group, the sixth and fifth decade of life were the most prevalent. Finally, the left side and a bilateral presentation were the most prevalent, with grade 2 in a predominant occurrence. A statistically significant difference was also found.

It is very important to know the degree of pneumatization that mastoid cells can present. This can allow us to relate, prevent or rule out pathologies associated with the temporal bone at this level. An adequate diagnosis and also the possibility of being participants in a multidisciplinary management with other areas of medicine may benefit the patient.

\section{CONCLUSIONS}

In conclusion, AEP pneumatization was found in $76.2 \%$ of the patients, the highest prevalence of AEP was found in grades 0 and 2, and our results were consistent with previous studies using conebeam CT. Knowing the degree of AEP pneumatization is important because we can prevent or rule out pathologies associated with the temporal bone at this level. Further studies using 
cone-beam CT including greater numbers of patients may be useful to define the frequency of this entity and its relationship with other variables.

\section{REFERENCES}

1. Ladeira DBS, Barbosa GLR, Nascimento MCC, Cruz AD, Freitas DQ, Almeida SM. Prevalence and characteristics of pneumatization of the temporal bone evaluated by cone beam computed tomography. Int $\mathbf{J}$ Oral Maxillofac Surg 2013;42:771-775.

2. Orhan K, Delilbasi C, Cebeci I, Paksoy C. Prevalence and variations of pneumatized articular eminence: a study from Turkey. Oral Surg Oral Med Oral Pathol Oral Radiol Endod. 2005;99:349-354.

3. Cinamon $U$. The growth rate and size of the mastoid air cell system and mastoid bone: a review and reference. Eur Arch Oto-Rhino-Laryngol Off J Eur Fed Oto-Rhino-Laryngol Soc EUFOS Affil Ger Soc OtoRhino-Laryngol - Head Neck Surg 2009;266:781-786.

4. Hill CA. Ontogenetic change in temporal bone pneumatization in humans. Anat Rec Hoboken NJ 2007 2011;294:1103-1115.

5. Groell R, Fleischmann B. The pneumatic spaces of the temporal bone: relationship to the temporomandibular joint. Dentomaxillofac Radiol 1999;28:69-72.

6. Lee D-H, Jung M-K, Yoo Y-H, Seo J-H. Analysis of unilateral sclerotic temporal bone: how does the sclerosis change the mastoid pneumatization morphologically in the temporal bone? Surg Radiol Anat SRA 2008;30:221-7.

7. Uzun C, Adali MK, Koten M, Yagiz R, Aydin S, Cakir B, et al. Relationship between mastoid pneumatization and middle ear barotrauma in divers. The Laryngoscope 2002;112:287-291.

8. Khojastepour L, Mirbeigi S, Ezoddini F, Zeighami N. Pneumatized Articular Eminence and Assessment of Its Prevalence and Features on Panoramic Radiographs. J Dent Tehran Iran 2015;12:235-42.

9. Miloglu O, Yilmaz AB, Yildirim E, Akgul HM. Pneumatization of the articular eminence on cone beam computed tomography: prevalence, characteristics and a review of the literature. Dentomaxillofac Radiol 2011;40:110-114.

10. Han S-J, Song MH, Kim J, Lee W-S, Lee H-K. Classification of temporal bone pneumatization based on sigmoid sinus using computed tomography. Clin Radiol 2007;62:1110-1118.
11. Yamakami I, Uchino Y, Kobayashi E, Yamaura A. Computed tomography evaluation of air cells in the petrous bone--relationship with postoperative cerebrospinal fluid rhinorrhea. Neurol Med Chir (Tokyo) 2003;43:334-338; discussion 339.

12. Shamshad MP, Kamath G, Babshet M, Srikanth HS, Doddamani L. Prevalence of temporal bone pneumatization in relation to temporomandibular joint A computed tomographic study. J Stomatol Oral Maxillofac Surg 2018;119:118-121.

13. Nascimento HAR, Visconti MAPG, Macedo P de TS, Haiter-Neto F, Freitas DQ. Evaluation of the zygomatic bone by cone beam computed tomography. Surg Radiol Anat SRA 2015;37:55-60.

14. Demirel O, Kaya E, Üçok CÖ. Evaluation of mastoid pneumatization using cone-beam computed tomography. Oral Radiol. 2014;30:92-97.

15. Delilbasi C, Orhan K, Icen M, Aksoy S, Horasan S, Kenan Kose S. Evaluation of articular eminence pneumatization using cone beam computed tomography. Minerva Stomatol 2013;62:349-354.

16. Al Faleh W, Ibrahim ME. A tomographic study of air cell pneumatization of the temporal components of the TMJ in patients with temporomandibular joint disorders. Egypt Dent J 2005;51:1835-1842.

17. Khojastepour L, Paknahad M, Abdalipur V, Paknahad M. Prevalence and Characteristics of Articular Eminence Pneumatization: A Cone-Beam Computed Tomographic Study. J Maxillofac Oral Surg 2018;17:339-344.

18. Şallı GA, Özcan İ, Pekiner FN. Prevalence of pneumatization of the articular eminence and glenoid fossa viewed on cone-beam computed tomography examinations in a Turkish sample. Oral Radiol 2020;36:40-46.

19. Bronoosh P, Shakibafard A, Mokhtare MR, Munesi Rad T. Temporal bone pneumatisation: a computed tomography study of pneumatized articular tubercle. Clin Radiol 2014;69:151-156.

20. Shokri A, Noruzi-Gangachin M, Baharvand $M$, Mortazavi H. Prevalence and characteristics of pneumatized articular tubercle: First large series in Iranian people. Imaging Sci Dent 2013;43:283-287.

21. Kishore M, Panat SR, Kishore A, Aggarwal A, Upadhyay N, Agarwal N. Prevalence of Zygomatic Air Cell Defect using Orthopantomogram. J Clin Diagn Res JCDR 2015;9:ZC09-11. 
22. Patil K, Mahima VG, Malleshi SN, Srikanth HS. Prevalence of zygomatic air cell defect in adults--a retrospective panoramic radiographic analysis. Eur $\mathbf{J}$ Radiol 2012;81:957-959.

23. Hofmann T, Friedrich RE, Wedl JS, Schmelzle R. [Pneumatization of the zygomatic arch on pantomography]. Mund- Kiefer- Gesichtschirurgie MKG 2001;5:173-179.
24. Carter LC, Haller AD, Calamel AD, Pfaffenbach AC. Zygomatic air cell defect (ZACD). Prevalence and characteristics in a dental clinic outpatient population. Dentomaxillofac Radiol 1999;28:116-122.

25. Jadhav AB, Fellows D, Hand AR, Tadinada A, Lurie AG. Classification and volumetric analysis of temporal bone pneumatization using cone beam computed tomography. Oral Surg Oral Med Oral Pathol Oral Radiol 2014;117:376-384. 